\title{
Magnetic resonance detects changes in phosphocholine associated with Ras activation and inhibition in NIH 3 T3 cells
}

\author{
SM Ronen, LE Jackson, M Beloueche and MO Leach \\ Cancer Research Campaign (CRC) Clinical Magnetic Resonance Research Group, Institute of Cancer Research, Royal Marsden Hospital, Downs Road, \\ Sutton, Surrey SM2 5PT, UK
}

Summary Ras is frequently mutated in cancer, and novel therapies are being developed to target Ras signalling. To identify non-invasive surrogate markers of Ras activation and inhibition, we used ${ }^{31} \mathrm{P}$ magnetic resonance spectroscopy (MRS) and investigated NIH 3 T3 cells compared to a mutant ras transfected counterpart. The MR spectra indicated that phosphocholine (PC) levels increased significantly from $3 \pm 2 \mathrm{fmol} \mathrm{cell}^{-1}$ in NIH 3 T3 cells to $13 \pm 4 \mathrm{fmol} \mathrm{cell}^{-1}$ in the transfected cells. The PC/NTP ratio increased significantly from $0.3 \pm 0.1$ to $0.7 \pm 0.3$. This could not be explained by either a faster proliferation rate or by alterations in cell cycle distribution. Both cell lines were treated with simvastatin, 17-AAG and R115777, agents which inhibit Ras signalling. Cell proliferation was inhibited in both cell lines. The spectrum of $\mathrm{NIH} 3 \mathrm{~T} 3$ cells was not affected by treatment. In contrast, in the ras transfected cells growth inhibition was associated with an average $35 \pm 5 \%$ drop in PC levels and a comparable drop in PC/NTP. Thus the MRS visible increase in phosphocholine is associated with Ras activation, and response to treatment is associated with partial reversal of phosphocholine increase in ras transfected cells. MRS might therefore be a useful tool in detecting Ras activation and its inhibition following targeted therapies. (C 2001 Cancer Research Campaign http://www.bjcancer.com

Keywords: magnetic resonance; ${ }^{31} \mathrm{P}$ spectroscopy; phosphocholine; Ras; NIH 3T3

Members of the ras oncogene family are mutated in a high proportion of human cancers (Kiarkis and Spandidos, 1995), leading to constitutive Ras activation. The overall incidence of ras mutations in cancer is of the order of $30 \%$ ranging from $80-90 \%$ in pancreatic cancers, $30-60 \%$ in colorectal cancers and $30-60 \%$ in lung cancers. Targeting Ras and the signalling pathways activated by the mutant oncogene is consequently one of the new approaches taken in the development of novel cancer therapies (Boral et al, 1998). Identifying direct or surrogate markers for the efficacy of such treatments could present another challenge. In this context, magnetic resonance spectroscopy (MRS), if able to detect metabolic changes associated with Ras activation or inhibition, could provide a useful non-invasive tool.

${ }^{1} \mathrm{H}$ and ${ }^{31} \mathrm{P}$ MRS can be utilized to detect choline, phosphocholine (PC) and glycerophosphocholine (GPC) and to monitor tumour phospholipid metabolism in treated cells and tumours (Podo, 1999 and references therein). At the same time, recent investigations of Ras signalling have demonstrated that the activities of enzymes involved in phosphatidylcholine metabolism, as well as the levels of several choline-containing metabolites are altered following Ras activation. An increase in cellular choline, phosphocholine as well as diacylglycerol (DAG) and GPC have been reported in ras transfected NIH 3T3 cells, oocytes, and C3H10T cells (Lacal et al, 1987; Price et al, 1989; Lacal, 1990; Teegarden et al, 1990; Ratnam and Kent, 1995). These variations have been explained by changes in the activities of choline kinase or CTP-PC cytidyltransferase

Received 11 September 2000

Revised 28 November 2000

Accepted 7 December 2000

Correspondence to: SM Ronen
(Teegarden et al, 1990; Ratnam and Kent, 1995; Weiprecht et al, 1996); activation of a phosphatidylcholine (PdylCh) specific phospholipase C (Lopez-Barahona et al, 1990; Carnero et al, 1994; Bjorkoy et al, 1995; Podo et al, 1996); phospholipase D (Carnero et al, 1994) or phospholipase A2 (Lin et al, 1993; Heasley et al, 1997). Using MRS, an increase in PC levels was detected in Schwann cells, following transfection with $H$-ras combined with the SV40 large T antigen (Bhakoo et al, 1996), whereas the comparison of a series of human breast cancer cell lines has shown a correlation between an increasingly transformed phenotype and higher PC/GPC levels (Aboagye and Bhujwalla, 1999).

Using NIH 3T3 cells, a well established model for investigating ras transformation, the purpose of this work was to determine whether MRS can be used to detect the alterations in choline metabolism associated with ras transformation. Furthermore, we aimed to assess the usefulness of MRS in non-invasively monitoring response to novel therapies targeted at the Ras signalling pathways. By comparing NIH 3T3 cells with their mutant $H$-ras transfected counterparts we determined that MRS can detect a significant increase in PC levels following Ras activation. Subsequent to treatment with 3 different inhibitors of Ras signalling, this increase in $\mathrm{PC}$ was partially reversed in the ras transfected cell line. We speculate that PC or the PC/NTP ratio could be used as surrogate MRS markers for ras transformation and response to Ras targeting therapies.

\section{MATERIALS AND METHODS}

NIH 3 T3 mouse fibroblasts and D12Hras1C (D12H) cells transfected with the H-ras gene mutated at codon 12 were kindly provided by $\mathrm{C}$ Marshall and L Kelland. Cells were maintained in DMEM (Gibco UK) supplemented with 5\% horse serum, 
$80 \mathrm{U} \mathrm{ml}^{-1}$ penicillin, and $80 \mu \mathrm{g} \mathrm{ml}^{-1}$ streptomycin at $37^{\circ} \mathrm{C}$ in a $5 \%$ $\mathrm{CO}_{2}$ atmosphere.

To characterize cell proliferation, growth curves were determined by counting trypsinized cells every 24 h over 8 days using a Coulter Act 8 counter. Cell cycle analysis was performed on cells fixed in $70 \%$ ethanol, treated with $100 \mu \mathrm{g} \mathrm{ml}^{-1}$ RNase A in PBS and stained with $4 \mu \mathrm{g} \mathrm{ml}^{-1}$ propidium iodide, using an Elite ESP Beckman coulter cell sorter at $488 \mathrm{~nm}$. Data were analysed using the WinMdi and Cylchred software (University of Wales College of Medicine).

To determine total protein content, cells were lysed and protein content determined using a DC protein assay kit (Biorad) and measuring absorbance at $750 \mathrm{~nm}$ using BSA as standard. Alternatively, the protein precipitate obtained from cells extracted for MRS investigations was dissolved by heating to $60^{\circ} \mathrm{C}$ in $1 \mathrm{M} \mathrm{NaOH}$ and protein content determined as above. To inhibit Ras signalling cells were treated either with $20 \mu \mathrm{M}$ simvastatin (courtesy of Merck Sharp \& Dohme UK; stock solution prepared in DMSO and diluted 1:5000) for $24 \mathrm{~h}$ or with $1.3 \mu \mathrm{M}$ 17-AAG (courtesy of NCI; stock solution in DMSO and diluted 1:5000) for $30 \mathrm{~h}$, or with $1 \mu \mathrm{M}$ R 115777 (courtesy of Janssen; stock solution in water diluted 1:1000) for $72 \mathrm{~h}$. In every case appropriate carrier treated (DMSO or water) controls were used. To assess levels of protein expression ca. $2 \times 10^{6}$ trypsinized cells were lysed in $50 \mu \mathrm{l}$ sample buffer $(50 \%$ buffer II $(0.25 \mathrm{M}$ Tris base, $6.9 \mathrm{mM}$ sodium dodecylsulphate (SDS) at $\mathrm{pH} 6.8), 4 \%$ SDS, $2 \%$ dithiothreitol, (10\% glycerol, $5 \% \quad 0.1 \mathrm{M}$ phenylmethylsulphonylfluoride and water), and heated to $90^{\circ} \mathrm{C}$ for $5 \mathrm{~min}$. Samples were loaded onto a 10\% (for ERK, Raf, GAPDH) or $13 \%$ (for Ras) polyacrylamide gel, separated by electrophoresis and transferred onto an immobilon-P membrane for $1 \mathrm{~h}$ at $80 \mathrm{~mA}$ using transfer buffer (15\% methanol, $0.3 \%$ Tris, $1.44 \%$ glycine and water). Immunoblots were blocked overnight in 5\% non-fat milk in wash buffer $(0.01 \mathrm{M}$ Tris, $0.1 \mathrm{M} \mathrm{NaCl}$ at $\mathrm{pH} 7.5)$ and probed for $1 \mathrm{~h}$ with one of the following: anti-Ras mouse monoclonal antibody (Transduction Laboratories USA); anti-Raf-1 rabbit polyclonal antibody (Santa Cruz Biotechnology USA); anti-ERK rabbit polyclonal antibody (New England Biolabs USA); anti-P-ERK mouse monoclonal antibody (Sigma UK); anti-GAPDH mouse monoclonal antibody (Chemicon International USA). Specific antigen-antibody interactions were detected with horseradish peroxidase-linked secondary antibody using enhanced chemiluminescence Western blotting detection reagents (Amersham Pharmacia Biotech UK).

To obtain an MR spectrum $2-4 \times 10^{7}$ cells in logarithmic phase were extracted as previously described (Tyagi et al, 1996; Ronen et al, 1999). Briefly, cells were rinsed with ice cold saline, then covered with ice-cold methanol, scraped off the culture flask surface, collected and vortexed. An equal volume of chloroform was then added followed by an equal volume of de-ionized water. Following phase separation and solvent removal samples were stored at $-80^{\circ} \mathrm{C}$. Prior to acquisition of the MRS spectra the water soluble metabolites were resuspended in $\mathrm{D}_{2} \mathrm{O}$ with $10 \mathrm{mM}$ EDTA at $\mathrm{pH} 8.2$ and the lipids were resuspended in $\mathrm{CDCl}_{3}$ supplemented with methanolic EDTA. MRS spectra were acquired at room temperature on a $400 \mathrm{MHz}$ Bruker spectrometer at $161 \mathrm{MHz}$ using a $90^{\circ}$ flip angle, a $7 \mathrm{~s}$ relaxation delay and broad band proton decoupling during acquisition. Metabolite contents were determined by integration, normalized relative to an internal reference (methylenediphosphonic acid in the case of water soluble metabolites and trimethylphosphate in the case of lipids) and corrected for saturation and the number of cells extracted.
A

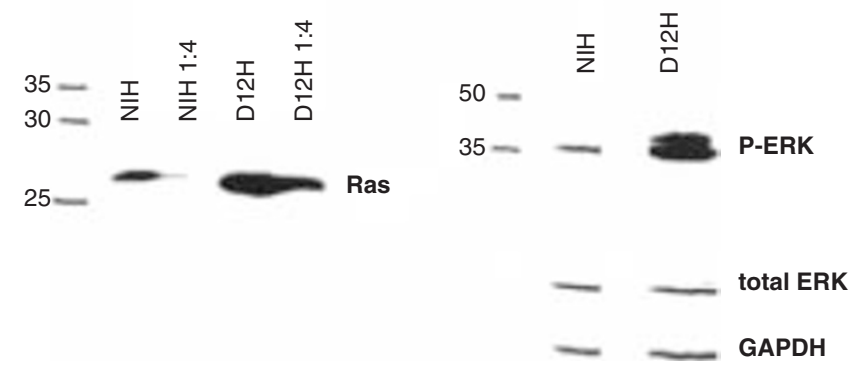

Figure 1 Western blot analysis determining expression of $(\mathbf{A})$ Ras and $(\mathbf{B})$ phosphorylated ERK and total ERK proteins in NIH 3T3 (NIH) cells and D12H ras-transfected cells. GAPDH was used to confirm equal sample loading. Lanes marked 1:4 were loaded with sample diluted 1:4 relative to the neighbouring lane

Results represent an average of at least 3 repetitions and are expressed as mean $\pm \mathrm{SD}$. Statistical significance was determined using one way ANOVA (Arcus Quickstat - Longman Software Publishing) and differences were assumed to be significant when $P<0.05$.

\section{RESULTS}

Western blots confirmed that Ras levels were higher in the ras transfected D12H cell line (Figure 1A). To determine the level of signalling through the Ras-Raf-MEK-ERK pathway the levels of both total ERK, and the phosphorylated form of ERK were determined by Western blotting. As illustrated in Figure 1B the levels of phosphorylated ERK were higher in the ras transfected D12H cells whereas total ERK levels indicate that the overall protein levels were not substantially altered following transfection. Western blotting for GAPDH was used to confirm equal loading of samples.

Cell growth was characterized by determining the proliferation rate of the cells as well as the cell cycle distribution. We determined that the doubling time was $28 \pm 4$ hours for NIH 3 T3 cells and $32 \pm 4$ hours for D12H cells $(n=8, P=0.07)$. The cell cycle distribution of exponentially growing NIH 3 T3 cells was $64 \pm 8 \%$ in $\mathrm{G} 1,7 \pm 3 \%$ in $\mathrm{G} 2$ and $29 \pm 6 \%$ in S phase. In the D12H cells the cell cycle distribution was altered: $40 \pm 4 \%$ of cells were in $\mathrm{G}_{1}$, $20 \pm 5 \%$ of cells were in $\mathrm{G}_{2}$ and $40 \pm 5 \%$ of cells were in $\mathrm{S}$ phase during the mid-logarithmic phase $\left(P<0.03\right.$ for $\left.\mathrm{G}_{1}\right)$.

Protein content was determined from cells extracted for this purpose and confirmed from protein precipitates obtained following cell extractions for MRS. The protein content of NIH $3 \mathrm{~T} 3$ cells was $249 \pm 28 \mathrm{pg}$ cell $^{-1}$ and increased significantly to $391 \pm 61 \mathrm{pg}$ cell $^{-1}$ in D12H cells $(P<0.001)$.

Figure 2 illustrates the ${ }^{31} \mathrm{P}$ MRS spectra obtained from extracts of NIH 3T3 and D12H cells. To rule out the effects of cell cycle arrest due to confluence, care was taken to perform all investigations when cells were in mid-logarithmic phase. The average PC content of NIH 3 T 3 cells was $3 \pm 2 \mathrm{fmol} \mathrm{cell}^{-1}(n=5)$ significantly increasing to $13 \pm 4 \mathrm{fmol} \mathrm{cell}^{-1}(n=5)$ in the D12H cells $(P<0.001)$. Cellular NTP content also increased upon ras transfection from $13 \pm 3 \mathrm{fmol} \mathrm{cell}^{-1}$ to $20 \pm 7 \mathrm{fmol} \mathrm{cell}^{-1}(P<0.04)$. The $\mathrm{PC} / \mathrm{NTP}$ ratio was $0.3 \pm 0.1$ in NIH $3 \mathrm{~T} 3$ cells and increased significantly to $0.7 \pm 0.3$ in the $\mathrm{D} 12 \mathrm{H}$ cells $(P<0.001)$. The GPC signal 


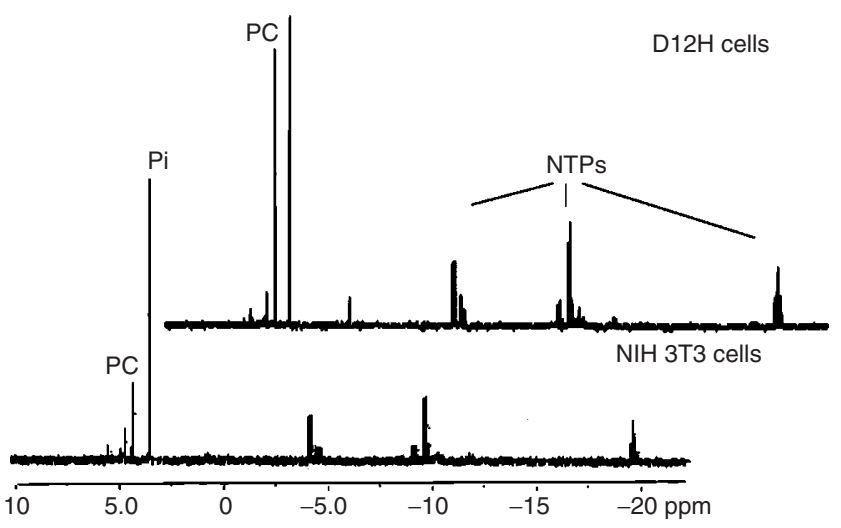

Figure $2{ }^{31} \mathrm{P}$ MRS spectra of the water soluble metabolites obtained from $\mathrm{NIH} 3 \mathrm{~T} 3$ and D12H cell extracts. The spectrum was plotted with a line broadening of $0.2 \mathrm{~Hz}$. PC: phosphocholine: Pi: inorganic phosphate; NTP: nucleoside triphosphates

was not always detectable by MRS and no statistically significant differences between the two cell lines could be observed.

To determine whether the levels of phosphatidylcholine were also altered following ras transformation, spectra were recorded from the chloroform phase of the cell extracts. No statistically significant difference between NIH 3 T3 and D12H cells was observed. Phosphatidylcholine represented $48 \pm 13 \%$ of total phospholipid content in NIH 3 T3 cells and $49 \pm 3 \%$ in D12H cells. This indicated that any change in the phospholipid content is below detection level by MRS, and cellular phosphatidylcholine level was not substantially affected by the increase in its precursor phosphocholine.

To further ascertain that our observations were correlated with the activation of Ras, and to determine whether MRS could be used to assess response to Ras targeting therapies, we treated both cell lines with 3 different inhibitors of the Ras pathway - R115777, simvastatin and 17-AAG. R115777 is an inhibitor of the farnesyltransferase enzyme which catalyses binding of a farnesyl moiety to the Ras protein (the farnesyl is required for localization of Ras to the cell membrane) (Zujewski et al, 2000). Simvastatin is an HMG-CoA reductase inhibitor which inhibits synthesis of the farnesyl moiety (Leonard et al, 1990). 17-AAG is an HSP90binding protein and causes depletion of several proteins including Raf, downstream of Ras in signalling to ERK (Schulte and Necker, 1998). Figure 3 illustrates the results of Western blotting for phosphorylated ERK. As indicated by the drop in P-ERK levels, all 3 inhibitors caused an inhibition of signalling through the RasRaf-MEK-ERK pathway. This inhibition was more marked in the case of D12H cells. Following treatment with 17-AAG a substantial drop in total Raf levels was also observed in both cell lines but total ERK was not altered following any of the treatments (data not shown).

Treatment with the Ras inhibitors also inhibited cell proliferation as illustrated in Figures 4A and 4E (NIH $3 \mathrm{~T} 3$ and D12H cells respectively). In the case of NIH $3 \mathrm{~T} 3$ cells, the number of cells per flask dropped to $72 \pm 15 \%$ following R 115777 treatment $(P<0.03), 61 \pm 15 \%$ following simvastatin treatment $(P<0.03)$, and $24 \pm 16 \%$ following $17-\mathrm{AAG}$ treatment $(P<0.01)$ relative to control. In the case of $\mathrm{D} 12 \mathrm{H}$ cells the number of cells per flask dropped to $62 \pm 15 \%$ following simvastatin treatment $(P<0.05)$, and to $32 \pm 4 \%$ following $17-\mathrm{AAG}$ treatment $(P<0.005)$ relative to control. Following treatment with R115777, a drop in cell

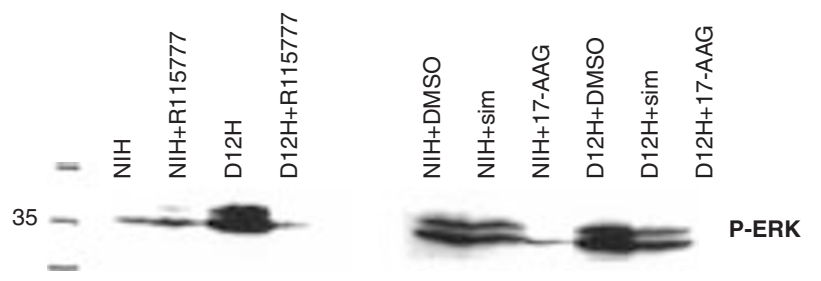

Figure 3 Western blot analysis determining expression of phosphorylated ERK in NIH 3T3 (NIH) and D12H cells treated with R115777, simvastatin (sim), and 17-AAG compared to matched controls

number per flask was observed but was not statistically significant (down to $88 \pm 12 \%, P=0.2$ ).

Treatment affected the cell cycle distribution in the same manner in both cell lines. R115777 and 17-AAG did not significantly alter the distribution in either cell line. In contrast simvastatin caused an arrest in the $\mathrm{G}_{1}$ phase of the cycle in both lines. In NIH $3 \mathrm{~T} 3$ cells, the cell cycle distribution following treatment was $83 \pm 4 \%$ in $\mathrm{G}_{1}, 4 \pm 1 \%$ in $\mathrm{G}_{2}$ and $13 \pm 4 \%$ in $\mathrm{S}$, and in the $\mathrm{D} 12 \mathrm{H}$ cells the distribution was $77 \pm 4 \%$ in $\mathrm{G}_{1}, 7 \pm 2 \%$ in $\mathrm{G}_{2}$ and $16 \pm 2 \%$ in $\mathrm{S}$ phase. Total protein content was not significantly affected by treatment in either cell line.

The MRS spectra of treated and control cell extracts indicated that for NIH 3T3 cells, the inhibition of Ras signalling and cell growth was not accompanied by any significant changes in the metabolites present in the ${ }^{31} \mathrm{P}$ MRS spectrum (Figure 4B-D). Within experimental error PC and NTP levels remained constant following all 3 treatments. In contrast, in the case of D12H rastransfected cells, the inhibition in cell growth and Ras signalling were accompanied by a significant drop in the levels of PC (Figure $4 \mathrm{~F})$. PC content dropped from $17 \pm 5$ in DMSO-treated controls to $11 \pm 1 \mathrm{fmol} \mathrm{cell}^{-1}$ following treatment with simvastatin $(P<0.02)$ and to $11 \pm 1 \mathrm{fmol} \mathrm{cell}^{-1}$ following treatment with 17-AAG $(P<$ $0.01)$. The increase observed in PC levels in the DMSO treated controls versus untreated control $(13 \pm 3$ versus $17 \pm 5)$ was not statistically significant $(P=0.3)$ The levels of NTP in the treated $\mathrm{D} 12 \mathrm{H}$ cells remained unchanged within experimental error (Figure $4 \mathrm{G}$ ) thus PC/NTP (Figure 4H) dropped significantly from $0.8 \pm 0.1$ in DMSO treated controls to $0.4 \pm 0.1$ following treatment with 17-AAG $(P<0.04)$ and to $0.6 \pm 0.1$ following simvastatin treatment $(P<0.03)$. Treatment with R115777 was also accompanied by a drop in PC from $13 \pm 4$ to $8 \pm 6 \mathrm{fmol} \mathrm{cell}^{-1}$, as well as a drop in PC/NTP from $0.7 \pm 0.3$ to $0.4 \pm 0.1$ but these did not reach statistical significance $(P=0.06)$.

\section{DISCUSSION}

To assess the effect of Ras activation and its inhibition using MRS we chose to concentrate on the extensively studied NIH 3T3 mouse fibroblast line and a mutant ras-transfected counterpart. By Western blotting for Ras and phosphorylated ERK, we confirmed that Ras signalling was increased in the transfected D12H cells relative to the parent NIH 3 T3 line. The MRS investigations of cell extracts showed a significant difference in metabolite content following ras transfection. NTP levels were higher in the ras transfected cells, but the most significant difference was in phosphocholine content which was more than 4 fold higher per cell in $\mathrm{D} 12 \mathrm{H}$. If metabolite content was normalized to $\mathrm{mg}$ protein, NTP content was unaltered by Ras (both cell lines contain 
(A)

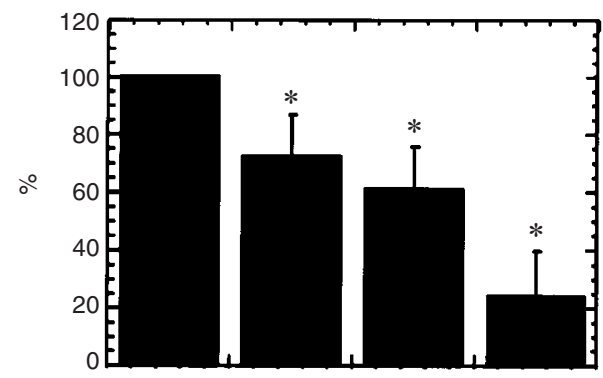

(B)

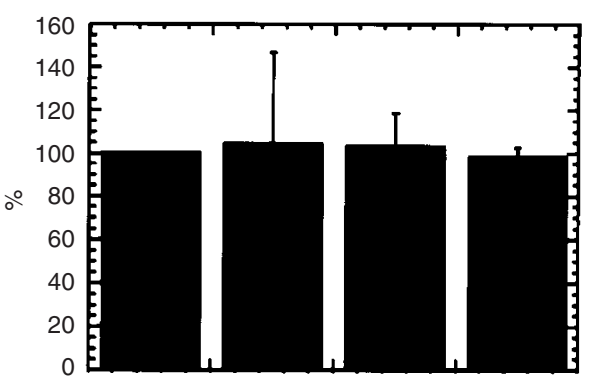

(C)

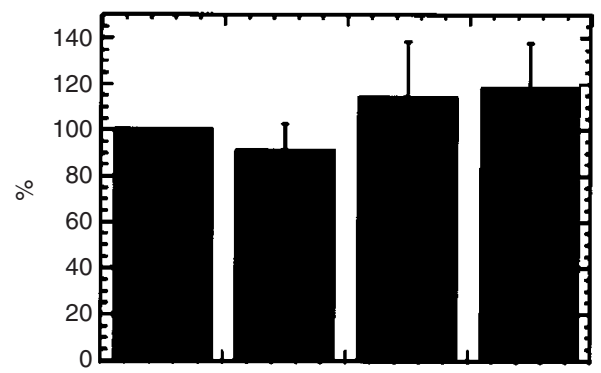

(D)

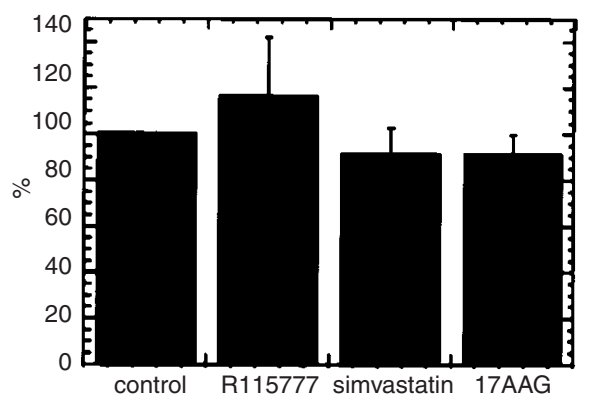

(E)

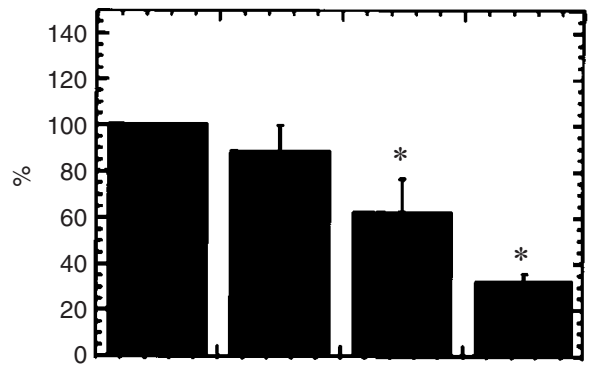

(F)

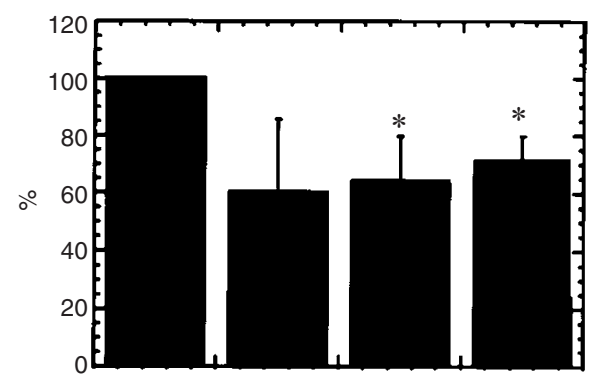

(G)

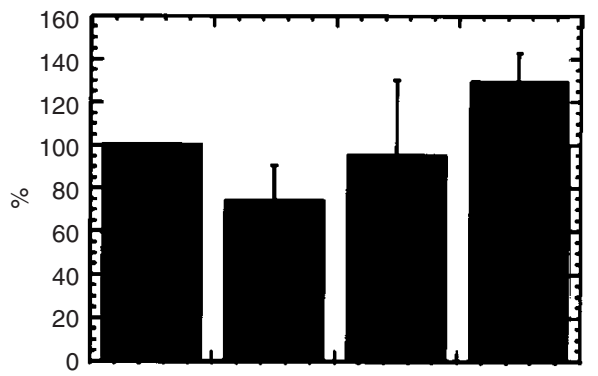

(H)

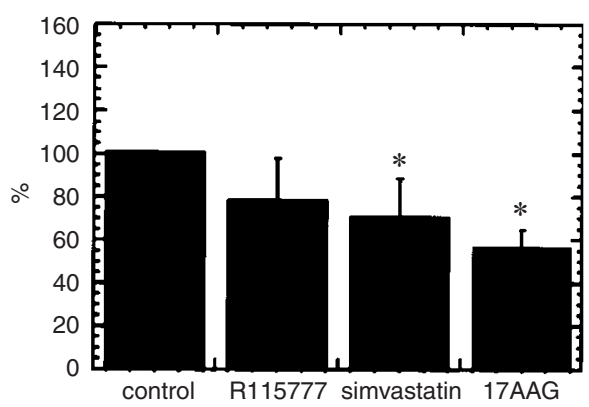

Figure 4 NIH 3T3 cells (A-D) and D12H cells (E-H) following treatment with R115777, simvastatin and 17-AAG. A and E represent \% cell number per flask following treatment relative to control. B and $\mathbf{F}$ represent $\% \mathrm{PC}$ content per cell relative to control. $\mathbf{C}$ and $\mathbf{G}$ represent \% NTP content per cell relative to control. D and $\mathbf{H}$ represent \% PC/NTP content per cell relative to control. Results represent the average change of 3 experiments relative to their matched controls (not the relative change in average values). ${ }^{*}$ Signifies statistical significance $(P<0.05)$

5 nmoles $\mathrm{mg}^{-1}$ protein). However, PC levels showed an almost 3 -fold increase from $12 \mathrm{nmol} \mathrm{mg}^{-1}$ protein in the NIH $3 \mathrm{~T} 3$ cell to $33 \mathrm{nmol} \mathrm{mg}{ }^{-1}$ protein in the $\mathrm{D} 12 \mathrm{H}$ line. The average $\mathrm{PC} / \mathrm{NTP}$ ratio, a parameter independent of cell number or protein content, also increased significantly by more than 2 -fold indicating that this ratio could serve as an MRS marker of Ras activation.
Previous MRS work has shown that PC levels can be affected by the proliferation state of the cells, with a drop in PC content observed in quiescent cells (Ronen et al, 1992; Podo, 1999). To avoid this problem care was taken to compare cells which were in the logarithmic phase of their growth, excluding cell populations which could be arrested due to confluence or nutrient deprivation. 
The increase in PC levels in transformed cells and tumours has been postulated as resulting from an increase in phospholipid synthesis to produce membranes required during cell division (Negendank, 1992; Podo, 1999). Our results show that the ras-transfected cell line which has a higher PC content, has a doubling time comparable within experimental error to the doubling time of the control cells. Thus, in this model, PC levels were not associated with altered doubling time. This observation is in agreement with some previously published data (Ting et al, 1996; Aboagye and Bhujwalla, 1999).

Previous MRS work has also shown a correlation between S phase fraction and PC levels (Smith et al, 1991). We observed a shortening of the $\mathrm{G}_{1}$ phase of the cell cycle in the ras-transfected $\mathrm{D} 12 \mathrm{H}$ cells. This probably results from the control by Ras of cyclin D (Liu et al, 1995; Gille and Downward, 1999). We cannot rule out that in our cells this drop in $G_{1}$ contributes to the observed increase in PC. However this is probably not the only explanation for our results: even if PC levels were undetectable during the $G_{1}$ phase with $P C$ originating exclusively from cells in $\mathrm{G}_{2}+\mathrm{S}$, the observed increase in the $\mathrm{G}_{2}+\mathrm{S}$ fraction from $36 \%$ to $60 \%$ following ras transfection would not be sufficient to explain the 4-fold increase in PC content per cell observed in the $\mathrm{D} 12 \mathrm{H}$ cells.

To further confirm that the increase in PC levels was due to Ras activation and to assess whether MRS could be used to detect the effects of Ras targeting therapies we treated both cell lines with 3 inhibitors of the Ras signalling pathway. We chose 2 inhibitors which would affect all pathways downstream of Ras (simvastatin and R115777) and a third inhibitor which should primarily affect the Ras-Raf-MEK-ERK pathway by depleting Raf (17-AAG). Whereas the spectrum of NIH 3T3 cells was not affected by treatment, D12H cells showed a drop in PC levels after treatment. The 3 inhibitors affected cell viability and cell cycle distribution of the control and transfected cell lines in the same way, ruling out differential response to treatment as an explanation of our results. Our findings lead to the conclusion that the MR detectable drop in PC is associated with inhibition in Ras signalling and cell proliferation only in the cells which over-expressed ras. This indicates that the initial increase in PC and PC/NTP and its subsequent partial drop following treatment probably reflect the presence of the mutant activated Ras protein.

Our results require further confirmation in other models, including human cell lines expressing mutant Ras. Nonetheless, this study indicates that MRS could be useful in noninvasively monitoring Ras activation as well as response to novel, Ras targeting therapies, with phosphocholine and PC/NTP levels serving as surrogate markers for mutant Ras activity.

\section{ACKNOWLEDGEMENTS}

CRC funding is gratefully acknowledged by SMR and MOL (grant number SP SP1780/0103).

\section{REFERENCES}

Aboagye EO and Bhujwalla ZM (1999) Malignant transformation alters membrane choline phospholipid metabolism of human mammary epithelial cells. Cancer Res 59: 80-84

Bhakoo KK, Williams SR, Florian CL, Land H and Noble MD (1996) Immortalization and transformation are associated with specific alternations in choline metabolism. Cancer Res 56: 4630-4634
Bjorkoy G, Overvatn A, Diaz-Meco MT, Moscat J and Johansen T (1995) Evidence for a bifurcation of the mitogenic signaling pathway activated by ras and phosphatidylcholine-hydrolyzing phsopholipase C. J Biol Chem 270: 21299-21306

Boral AL, Dessain S and Chabner BA (1998) Clinical evaluation of biologically targeted drugs: obstacles and opportunities. Cancer Chemother Pharmacol 42: s3-s21

Carnero A, Cuadrado A, Del Peso L and Lacal JC (1994) Activation of D phospholipase by serum stimulation and ras-induced transformation in NIH3T3 cells. Oncogene 9: 1387-1395

Gille H and Downward J (1999) Multiple ras effector pathways contribute to G1 cell cycle progression. $J$ Biol Chem 274: 22033-22040

Heasley LE, Thaler S, Nicks M, Price B, Skorecki K and Nemenoff RA (1997) Induction of cytosolic phospholipase A2 by oncogenic Ras in human non-small cell lung cancer. J Biol Chem 272: 14501-14504

Kiarkis H and Spandidos DA (1995) Mutations of ras genes in human tumours (review). Int J Oncol 7: 413-421

Lacal JC (1990) Diacylglycerol production in Xenopus laevis oocytes after microinjection of $\mathrm{p} 21$ ras proteins is a consequence of activation of phosphatidylcholine metabolism. Mol Cell Biol 10: 333-340

Lacal JC, Moscat J and Aaronson SA (1987) Novel source of 1,2-diacylglycerol elevated in cells transformed by Ha-ras oncogene. Nature 330: 269-272

Leonard S, Beck L and Sinensky M (1990) Inhibition of isoprenoid biosynthesis and the post-translational modification of pro-p21. J Biol Chem $\mathbf{2 6 5}$ : $5157-5160$

Lin LL, Wartmann M, Lin AY, Knopf JL, Seth A and Davis RJ (1993) cPlA2 is phosphorylated and activated by MAP kinase. Cell 72: 269-278

Liu JJ, Chao JR, Ming-Chung J, Sun-Yu N, Yen JJY and Yang-Yen HF (1995) Ras transformation results in an elevated level of cyclin D1 and accelerationof G1 progression in NIH 3 T3 cells. Mol Cell Biol 15: 3654-3663

Lopez-Barahona M, Kaplan PL, Cornet ME, Diaz Meco MT, Larrodera P, Diaz-Laviada I, Municiao AM and Moscat J (1990) Kinetic evidence of a rapid activation of phosphatidylcholine hydrolysis by Ki-ras oncogene. Possible involvement in late steps of mitogenic cascade. J Biol Chem $\mathbf{2 6 5}$ : 9022-9026

Negendank W (1992) Studies of human tumours by MRS: a review. NMR Biomed $\mathbf{5}$ : 303-324

Podo F (1999) Tumour phospholipid metabolism. NMR in Biomed 12: 413-439

Podo F, Ferretti A, Knijn A, Zhang P, Ramoni C, Barletta B, Pini C, Baccarini S and Pulciani S (1996) Detection of phosphatidylcholine-specific phospholipase C in NIH-3T3 fibroblasts and their H-ras transformants: NMR and immunochemical studies. Anticancer Res 16: 1399-1412

Price BD, Morris JDH, Marshall CJ and Hall A (1989) Stimulation of phosphatidylcholine hydrolysis, diacylglycerol release and arachidonic acid production by oncogenic ras is a consequence of protein kinase $\mathrm{C}$ activation. J Biol Chem 264: 16638-16643

Ratnam S and Kent C (1995) Early increase in choline kinase activity upon induction of the H-ras oncogene in mourse fibroblast cell lines. Arch Biochem Biophys 323: 313-322

Ronen SM, Rushkin E and Degani H (1992) Lipid metabolism in large T47D human breast cancer spheroids: 31P- and 13C-NMR studies of choline and ethanolamine uptake. Biochim Biophys Acta 1138: 203-212

Ronen SM, DiStefano F, McCoy CL, Robertson D, Smith TAD, Al-Saffar NM, Titley J, Cunningham DC, Griffiths JR, Leach MO and Clarke PA (1999) Magnetic resonance detects metabolic changes associated with chemotherapyinduced apoptosis. Br J Cancer 80: 1035-1041

Schulte TW and Necker LM (1998) The benzoquinone ansamycin 17-allylamino17-demethoxygeldanamycin binds to HSP90 and shares important biologic activities with geldanamycin. Cancer Chemother Pharmacol $\mathbf{4 2}$ 273-279

Smith TA, Eccles S, Ormerod MG, Tombs AJ, Titley JC and Leach MO (1991) The phosphocholine and glycerophosphocholine content of an oestrogen-sensitive rat mammary tumour correlates strongly with growth rate. Br J Cancer 64: 821-826

Teegarden D, Taparowsky EJ and Kent C (1990) Altered phosphatidylcholine metabolism in C3H10T cells transfected with the Harvey-ras oncogene. J Biol Chem 265: 6042-6047

Ting Y-LT, Sherr D and Degani H (1996) Variations in energy and phosphlipid metabolism in normal and cancer human mammary epithelial cells. Anticancer Res 16: 1381-1388

Tyagi RK, Azrad A, Degani H and Salomon Y (1996) Simultaneous extraction of cellular lipids and water-soluble metabolities: evaluation by NMR spectroscopy. Magn Reson Med 35: 194-200 
Weiprecht M, Weider T, Paul C, Geilen CC and Orfanos CE (1996) Evidence for phosphorylation of CTP:phosphocholine cytidyltrasferase by multiple proline directed protein kinases. J Biol Chem 271: 9955-9961

Zujewski J, Horak ID, Bol CJ, Woestenborghs R, Bowden C, End DW,

Piotrovsky VK, Chiao J, Belly RT, Todd A, Kopp WC, Kohler DR, Chow C,
Noone M, Hakim FT, Larkin G, Gress RE, Nussenblatt RB, Kremer AB and Cowan KH (2000) Phase I and Pharmacokinetic Study of Farnesyl Protein Transferase Inhibitor R115777 in Advanced Cancer. J Clin Oncol 18: 927-928 